\title{
Synchronous colorectal liver metastases: therapeutic considerations
}

\author{
Michael R. Driedger ${ }^{1}$, Sean P. Cleary ${ }^{2}$, David M. Nagorney ${ }^{2}$ \\ ${ }^{1}$ Division of Hepatobiliary and Pancreatic Surgery, Atrium Health, Charlotte, NC, USA; ${ }^{2}$ Division of Hepatobiliary and Pancreatic Surgery, Mayo \\ Clinic, Rochester, MN, USA \\ Correspondence to: Michael R. Driedger. Division of Hepatobiliary and Pancreatic Surgery, Atrium Health, Charlotte, NC, USA. \\ Email: mdriedge@ualberta.ca. \\ Comment on: Lillemoe HA, Vauthey JN. Surgical approach to synchronous colorectal liver metastases: staged, combined, or reverse strategy. \\ Hepatobiliary Surg Nutr 2020;9:25-34.
}

Submitted Jun 16, 2021. Accepted for publication Jun 28, 2021.

doi: 10.21037/hbsn-21-239

View this article at: https://dx.doi.org/10.21037/hbsn-21-239

More than $50 \%$ of patients will develop colorectal cancer (CRC) liver metastases (CRCLM) during the course of their disease, while $15-25 \%$ of patients will have metastatic disease present at the time of initial diagnosis. Resection of CRCLM is possible in approximately one-in-four patients and 5-year overall survival (OS) rates have improved to nearly $60 \%$ in selected patients who undergo resection.

The management of synchronous colorectal liver metastases (SCRLM) is complex and nuanced, mandating a multidisciplinary approach. Indeed, the precise sequencing of systemic and locoregional therapies must be individualized to the patient with thoughtful consideration anatomic factors, patient factors, disease distribution, disease biology and the nature of presentation. Patients can undergo simultaneous or staged resection.

In their paper, Lillemoe and Vauthey eloquently outline the indications, merits, and concerns as it pertains to the colorectal first approach, liver first approach, and simultaneous resection (1). We would like to complement them on their thoughtful commentary highlighting the importance of individualization and stressing the complexity of major liver surgery. In their algorithm, preoperative systemic therapy is administered in most patients. It is likewise our respective institutional practice to employ neoadjuvant systemic therapy in the majority of patients who present with synchronous CRCLM. The principal advantages being patient selection, assessment of tumor biology, and demonstration of response to chemotherapy (biochemical, radiographic, and pathologic in the resected specimen).

We too have institutional preferences for a liver first or simultaneous resection, following neoadjuvant therapy in appropriately selected patients. The rationale being early treatment of systemic disease which serves as the foremost determinant of OS. In our recently published manuscript, 273 consecutive cases of synchronous resection of both the CRC primary and CRCLM were retrospectively reviewed (2). Total morbidity was $39.2 \%$, while colorectal specific and liver specific morbidity occurred in $23.8 \%$ and $8.4 \%$ of patients respectively. The anastomotic leak rate was low at $2.2 \%$. Thirty- and 90 -day mortality was $1.1 \%$ and $4.0 \%$ respectively.

When contemplating a simultaneous resection, the magnitude of both the liver and colorectal resection must be considered. This involves an independent and summative evaluation of risk and morbidity, balancing the appropriateness of a simultaneous versus staged approach. A diverting ostomy should be suitably employed to reduce the risk of pelvic sepsis, symptomatic leak and total anastomotic leak rates. In our series, hepatic and colorectal resections were stratified as major and minor. Combining a major liver with major colorectal resection was associated with a significant increase in major morbidity and 90-day mortality. Furthermore, greater than one-third of these patients were prevented from receiving adjuvant chemotherapy secondary to postoperative morbidity. Our data supported the safety of simultaneous resection, even in the setting of a major hepatic resection, but clearly demonstrated that 
combination with major colorectal resection should be avoided.

In a previous study from our institution, Shubert et al. reviewed ACS-NSQIP data from over 43,000 patients (3). Synchronous resection of "major" hepatectomy and "highrisk" colorectal resection was associated increased rates of major morbidity and mortality. Synchronous resections, when compared to cumulative asynchronous outcomes, revealed decreased mortality following minor hepatectomy and low- or high-risk colorectal resection.

Prior publications have reported on the safety of simultaneous operative intervention with equivalent cumulative morbidity. However, this is most frequently performed in the setting of lesser hepatic resections. The benefits of a synchronous approach include a single operation and general anesthetic, decreased cumulative length of hospital stay and associated reduction in resource utilization and expenditure. On the contrary, several recent publications utilizing national database records demonstrate increased morbidity with the simultaneous approach $(4,5)$. A major limitation when reviewing the data is the clinical relevance of increased minor/total morbidity, or an increase in length-of-stay, on long-term and oncologic outcomes. Additionally, the duration of time in which systemic therapy is held to accommodate a second operation is rarely considered. In our dataset, postoperative complications delayed or precluded adjuvant therapy in just under onein-four patients (2). The mean time to initiation of therapy in the absence of a delay was 6.3 versus 11.1 weeks if a delay occurred, with no difference in OS. Failure to receive chemotherapy as a result of postoperative morbidity resulted in increased mortality. While the precise contribution to the elevated mortality rate from morbidity and failure to receive adjuvant therapy could not be determined, this is a clinical scenario to be prevented. Several publications support the negative influence of post-operative morbidity on both long-term and oncologic outcomes $(6,7)$.

One point that warrants additional commentary is the fact that liver resection can be divided into two further categories, those requiring a single or two-stage approach. In the conventional two-stage approach, the future liver remnant (FLR) is rendered disease free and allowed to hypertrophy, followed by the second, larger liver resection. The colorectal resection can be combined with either stage, however, the second stage is typically a major hepatectomy. Therefore, a low-risk colorectal resection combined with a lesser, stage-one liver resection is very reasonable. The likelihood of significant colorectal specific morbidity precluding the second stage is very low.

A second point that requires attention is the critical importance of specialist surgeon (hepatobiliary and colorectal surgery) involvement in the care of these complex patients. Subspeciality surgical care is associated with superior patient outcomes. It is ill-advised to subject the patient to increased risk of postoperative morbidity when expert care is available but not sought.

Thus, a prescriptive algorithm cannot be applied to all patients as therapy is individualized to each unique presentation. Multidisciplinary teams must be flexible and deliberative in their approach to the sequencing of systemic and locoregional therapy. Neoadjuvant systemic therapy is likely appropriate for most patients. Simultaneous resection can be performed safely, even in the setting of major liver resection. However, the data is most supportive of simultaneous resection when combining a lesser liver and colorectal resection. The magnitude of the cumulative procedure must be considered as it is the combination that acts as a primary driver of postoperative morbidity.

\section{Acknowledgments}

Funding: None.

\section{Footnote}

Provenance and Peer Review: This article was commissioned by the editorial office of Hepatobiliary Surgery and Nutrition. The article did not undergo external peer review.

Conflicts of Interest: All authors have completed the ICMJE uniform disclosure form (available at https://hbsn. amegroups.com/article/view/10.21037/hbsn-21-239/coif). The authors have no conflicts of interest to declare.

Ethical Statement: The authors are accountable for all aspects of the work in ensuring that questions related to the accuracy or integrity of any part of the work are appropriately investigated and resolved.

Open Access Statement: This is an Open Access article distributed in accordance with the Creative Commons Attribution-NonCommercial-NoDerivs 4.0 International License (CC BY-NC-ND 4.0), which permits the noncommercial replication and distribution of the article with the strict proviso that no changes or edits are made and the original work is properly cited (including links to both 
the formal publication through the relevant DOI and the license). See: https://creativecommons.org/licenses/by-nc$\mathrm{nd} / 4.0 /$.

\section{References}

1. Lillemoe HA, Vauthey JN. Surgical approach to synchronous colorectal liver metastases: staged, combined, or reverse strategy. Hepatobiliary Surg Nutr 2020;9:25-34.

2. Driedger MR, Yamashita TS, Starlinger P, et al. Synchronous resection of colorectal cancer primary and liver metastases: an outcomes analysis. HPB (Oxford) 2021;23:1277-84.

3. Shubert CR, Habermann EB, Bergquist JR, et al. A NSQIP Review of Major Morbidity and Mortality of Synchronous Liver Resection for Colorectal Metastasis Stratified by Extent of Liver Resection and Type of Colorectal Resection. J Gastrointest Surg

Cite this article as: Driedger MR, Cleary SP, Nagorney DM. Synchronous colorectal liver metastases: therapeutic considerations. HepatoBiliary Surg Nutr 2021;10(5):711-713. doi: 10.21037/hbsn-21-239
2015;19:1982-94.

4. Concors SJ, Vining CM, Saur NM, et al. Combined Proctectomy and Hepatectomy for Metastatic Rectal Cancer Should be Undertaken with Caution: Results of a National Cohort Study. Ann Surg Oncol 2019;26:3972-9.

5. Jones TJ, Murphy AE, Tameron A, et al. Trends and Outcomes of Synchronous Resection of Colorectal Metastasis in the Modern Era-Analysis of Targeted Hepatic NSQIP Database. J Surg Res 2019;238:35-40.

6. Dorcaratto D, Mazzinari G, Fernandez M, et al. Impact of Postoperative Complications on Survival and Recurrence After Resection of Colorectal Liver Metastases: Systematic Review and Meta-analysis. Ann Surg 2019;270:1018-27.

7. Yin Z, Huang X, Ma T, et al. Postoperative complications affect long-term survival outcomes following hepatic resection for colorectal liver metastasis. World J Surg 2015;39:1818-27. 